$$
\begin{gathered}
\text { CERN-TIS-98-O18-CF-RP } \\
\text { Sie } 9847
\end{gathered}
$$

EUROPEAN LABORATORY FOR PARTICLE PHYSICS

CERN LIBRARIES, GENEVA

CERN/TIS-RP/98-18/CF

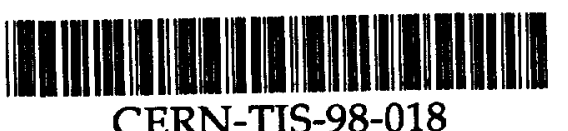

\title{
The Decommissioning of Accelerators: an Exercise in the Recycling of Radioactive Material
}

\author{
M. Höfert, J. W. N. Tuyn and D. Forkel-Wirth
}

\begin{abstract}
Compared with the number of nuclear power plants that will be decommissioned over the next few years accelerators are only a "small" source of radioactivity although at CERN the total amount of mostly metallic material activated in the operation of the accelerators is estimated to be of the order of 15 Mtons. Various existing approaches to classify and administer radioactive material will be presented with all of them clearly earmarked by the requirements of the nuclear cycle. There are however important differences between activation in reactors and accelerators that will be worked out. It will be shown that an attitude based on reuse or recycling of activated accelerator material should be preferred to the elimination as radioactive waste.
\end{abstract}

Invited paper at the Fifteenth International Conference on the Applications of Accelerators in Research and Industry University of North Texas, Denton, 4 to 7 November 1998. 



\section{INTRODUCTION}

Radioactive material in big quantities is always associated with nuclear power and known to the public as radioactive waste with all the negative image that it has developed over the years. National working groups as well as international committees generally consider the nuclear cycle correctly as the major source of man made radioactivity.

High-energy accelerators are usually big machines capable of accelerating electrons or protons beyond the energy of some tens of $\mathrm{MeV}$. When such beams interact with material nuclear processes will lead to the formation of radionuclides inducing radioactivity in the accelerator structure and the surrounding shielding.

This paper will concentrate on the particular aspects of radioactive material that is released from accelerators during maintenance or repair when no longer be needed. Whilst this concerns parts like activated vacuum chambers or other beam elements during the exploitation phase of an accelerator the amount of radioactive material can be considerable in cases where a whole accelerator complex is dismantled.

\section{CHARACTERIZATION OF RADIOACTIVITY IN ACCELERATORS}

A large experience in the activation processes around high-energy accelerators acquired over the last forty years has found its way into many publications. There are three main ways of activation that lead to a multitude of radionuclides in materials hit by beams of electrons or protons.

The classical path is via neutron induced nuclear reactions mostly in the form of a $(n, \gamma)$-process where the probability of formation of a particular radionuclide is as usual determined by the cross-section.

There are also inverse reactions $(\gamma, \mathbf{n})$ with usually small cross-sections hence only little importance in proton but naturally more important in electron accelerators.

The third and by far the most important pathway of inducing radioactivity in proton accelerators is the direct hadronic interaction of a high-energy particle with the nucleus of a target material. In these spallation reactions the products have always lower, in many cases much lower, atomic numbers than their target nucleus. Typical radioactive spallation products are ${ }^{3} \mathrm{H}$ and ${ }^{7} \mathrm{Be}$ but also stable helium nuclei are formed in these reactions.

Naturally all induced radioactivity decays according to the half-lives of the radionuclides created. As far as radioactive material is concerned that is subject to reuse, recycling or waste disposal, only relatively long-lived radionuclides are important. It is generally accepted that before any conditioning of radioactive material takes place a sufficiently long cooling time has elapsed such that at least the spallation product ${ }^{7} \mathrm{Be}$ with its half-life of 53 days has decayed.

In table 1 the most common induced radionuclides with half-lives longer than 60 days as identified for typical materials used in the construction of accelerators are listed: Metals are important construction materials for machines with iron magnets and copper or aluminum coils. Plastic material insulates power and signal cables. Cooling of construction elements with demineralized water is assured through tubing made from stainless steel. Iron, earth and concrete barriers provide biological shielding. Lead is seldom used around proton machines whilst it is an important shielding material against photons and highenergy electrons. Barytes concrete is rarely encountered as it is expensive, mechanically less stable than normal concrete, and giving rise to the ill reputed radionuclides of cesium. Other materials like silver are found only in small quantities mostly as impurity in lead.

The table illustrates the fact that with heavier target material the number of possible radionuclides increases and that in spallation reactions very low atomic number nuclei like tritium are formed with all heavier elements. 
TABLE 1: Commonly identified long lived radionuclides (Half-life $>60$ days) in materials activated around high-energy accelerators, their main reaction path(s) and radiation hazard.

\begin{tabular}{|c|c|c|c|}
\hline $\begin{array}{c}\text { Target } \\
\text { material }\end{array}$ & Radionuclide & Half-life & Main reaction path and radiation hazard \\
\hline Plastics & $\begin{array}{l}{ }^{3} \mathrm{H} \\
{ }_{36} \mathrm{Cl}\end{array}$ & $\begin{array}{l}12.2 \mathrm{y} \\
3 \cdot 10^{5} \mathrm{y}\end{array}$ & $\begin{array}{l}\text { Spallation; internal } \\
35 \mathrm{Cl}(\mathrm{n}, \gamma) \text {; internal }\end{array}$ \\
\hline Aluminum & $\begin{array}{l}\text { As above plus } \\
{ }^{14} \mathrm{C} \\
{ }^{22} \mathrm{Na} \\
{ }^{26} \mathrm{Al}\end{array}$ & $\begin{array}{l}5730 y \\
2.6 y \\
8 \cdot 10^{5} y\end{array}$ & $\begin{array}{l}{ }^{14} \mathrm{~N}(\mathrm{n}, \mathrm{p}) ;{ }^{17} \mathrm{O}(\mathrm{n}, \alpha) ; \text { Spallation; internal } \\
\text { Spallation; } 23 \mathrm{Na}(\gamma, \mathrm{n}) \text {; external } \\
{ }^{27} \mathrm{Al}(\gamma, \mathrm{n}) \text {; external }\end{array}$ \\
\hline $\begin{array}{l}\text { Steel, stainless } \\
\text { steel }\end{array}$ & $\begin{array}{l}\text { As above plus } \\
{ }^{46} \mathrm{Sc} \\
{ }^{44} \mathrm{Ti} \\
{ }^{54} \mathrm{Mn} \\
{ }^{55} \mathrm{Fe} \\
{ }^{56} \mathrm{Co} \\
{ }^{57} \mathrm{Co} \\
{ }^{58} \mathrm{Co} \\
{ }^{60} \mathrm{Co} \\
{ }^{63} \mathrm{Ni}\end{array}$ & $\begin{array}{l}84 \mathrm{~d} \\
48 \mathrm{y} \\
312 \mathrm{~d} \\
2.94 \mathrm{y} \\
77 \mathrm{~d} \\
270 \mathrm{~d} \\
72 \mathrm{~d} \\
5.27 \mathrm{y} \\
92 \mathrm{y}\end{array}$ & 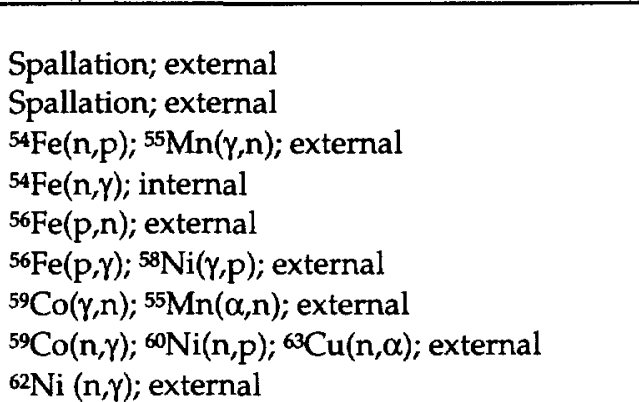 \\
\hline Copper & $\begin{array}{l}\text { As above plus } \\
65 \mathrm{Zn}\end{array}$ & $245 \mathrm{~d}$ & 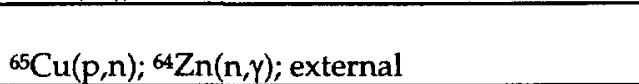 \\
\hline Lead & $\begin{array}{l}\text { As above plus } \\
{ }^{108} \mathrm{Ag} \\
110 \mathrm{~m} \mathrm{Ag} \\
204 \mathrm{Tl}\end{array}$ & $\begin{array}{l}127 y \\
254 \mathrm{~d} \\
3.8 \mathrm{y}\end{array}$ & $\begin{array}{l}{ }^{107} \mathrm{Ag}(\mathrm{n}, \gamma) ; \text { external } \\
{ }^{109} \mathrm{Ag}(\mathrm{n}, \gamma) ; \text { external } \\
{ }^{203} \mathrm{Tl}(\mathrm{n}, \gamma) ; \text { external }\end{array}$ \\
\hline Earth & $\begin{array}{l}\text { As above plus } \\
152 \mathrm{Eu} \\
{ }^{154} \mathrm{Eu}\end{array}$ & $\begin{array}{l}12.7 y \\
16 y\end{array}$ & 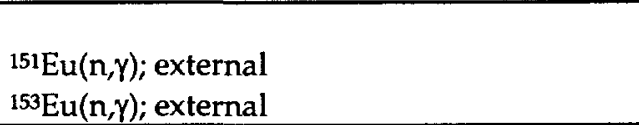 \\
\hline $\begin{array}{l}\text { Concrete } \\
\text { (barytes) }\end{array}$ & $\begin{array}{l}\text { As above plus } \\
{ }_{133} \mathrm{Ba} \\
{ }^{134} \mathrm{Cs} \\
{ }^{137} \mathrm{Cs}\end{array}$ & $\begin{array}{l}10.5 y \\
2.06 y \\
30 y\end{array}$ & $\begin{array}{l}{ }^{133} \mathrm{Ba}(n, \gamma) ; \text { external } \\
{ }^{133} \mathrm{Cs}(\mathrm{n}, \gamma) ;{ }^{134} \mathrm{Ba}(\mathrm{n}, \mathrm{p}) \text {; external, internal } \\
{ }^{137} \mathrm{Ba}(\mathrm{n}, \mathrm{p}) ;{ }^{138} \mathrm{Ba}(\gamma, \mathrm{p}) ; \text { external, internal }\end{array}$ \\
\hline
\end{tabular}

The inventory of radionuclides in accelerators is quite distinct from those identified in reactors. There are no fission products and alpha emitters but high-energy proton and electron accelerators induce rather beta/gamma radiation emitting isotopes instead, characterized by a predominance of positron emitters. As far as their radiological risk is concerned most of the radionuclides present only an external radiation hazard. A possible external exposure is determined by the dose rates at a certain distance from an activated material and is, in the case of voluminous items, a function of the distribution of the activity inside the piece and the self-shielding properties of the material. Internal exposure is the result of ingestion or inhalation of radioactive material. In view of the fact that solid materials around high-energy accelerators are activated in the bulk (minor) contamination risks exist only when surfaces are dusty or become corroded in case radioactive material is stored inappropriately.

With respect to the half-lives of the radionuclides there are a few very long lived isotopes that.are difficult to detect. Due to short activation periods (several years) compared with their long half-lives they are generally present only in small concentrations. One can estimate that after a decay time of about one year more than $80 \%$ of the activated solid materials (mostly metals) in a proton and more than $95 \%$ of those in an electron accelerator have specific activities of less than $100 \mathrm{~Bq} / \mathrm{g}$. In view of the low radiological hazard of such material and given the financial value of metallic scrap, recycling should be considered rather than disposal as radioactive waste. The cost of radioactive disposal has dramatically increased over the last years and bulky items like magnet yokes from accelerators pose a particular problem of conditioning before disposal can even be envisaged.

The possibility of reuse of radioactive material in a radiation environment is often stressed in the literature but is rather limited in practice. Hence, the cost of casting shielding blocks using radioactive iron is prohibitive and is much more expensive than buying new blocks made from virgin material.

\section{EXEMPTION VALUES AND CLEARANCE LEVELS}

It is a general concept in radiation protection that the use of small quantities of radioactivity is exempted from any regulatory control and subsequently needs no authorization. In many countries this however does not mean that exempted radioactivity can be disposed of, recycled or reused without any restriction.

Therefore the concept of exemption values (EV) has 
been extended introducing clearance levels (CL). These CLs being either unconditional or conditional would then permit the release of material as inactive either without any condition or under some restriction. However, at present such values are neither officially proposed in the EU Directive (1) nor in the International Atomic Energy Agency (IAEA) Basic Safety Standards (2) although it would be necessary to provide unconditional clearance levels (UCLs) to cope with an ever increasing amount of slightly radioactive solid and frequently metallic material for which a release free from any regulatory control would be reasonable.

Nevertheless, after having scrutinized a number of reports on the issue the IAEA have published UCLs in a Technical Document (3). There is a tendency to follow the most conservative exposure path when estimating the resulting doses in the handling such material or for the general public. Furthermore, considering the uncertainties of the models used IAEA's system of UCLs is based on five categories of radionuclides only. Clearance levels of specific activity range from 0.1 to $1.0,1$ to 10,10 to 100 , 100 to 1000 and 1000 to $10000 \mathrm{~Bq} / \mathrm{g}$ with representative values of $0.3,3,30,300$, and $3000 \mathrm{~Bq} / \mathrm{g}$. When proposing the UCLs the IAEA adopted three seemingly universally accepted criteria:

- individual doses to the average member of a critical group from likely exposure scenarios should be constraint to $10 \mu \mathrm{Sv} / \mathrm{a}$ and for unlikely scenarios to $100 \mu \mathrm{Sv} / \mathrm{a}$.

- the collective dose per year of practice involving cleared material should be less than about 1 man'Sv

- clearance levels should not be greater than exemption values in order to avoid the legal problem that a cleared material, because it is no longer exempted, falls again under regulatory control.

Table 2 places IAEA's EVs that are identical to those in the European Directive in a synopsis with a collection of unconditional and conditional clearance levels from various sources. The EVs in column 2 are up to two orders of magnitude higher than the UCLs in column 3 published in IAEA's Technical Document (3).

Columns 4 and 5 contain CLs that are only valid under specific boundary conditions. Conditional clearance of radioactivity has been practiced since long, is further developed in many countries like in CERN's host counties France and Switzerland, and will be discussed below.

The clearance condition for a mixture of radionuclides in a given material is calculated with the help of the following formula:

$$
\sum_{\mathrm{i}} A_{\mathrm{j}} / C L_{\mathrm{i}} \leq 1
$$

where $A_{\mathrm{i}}$ is the specific activity of radionuclide $\mathrm{i}$ and $C L_{\mathrm{i}}$ the corresponding unconditional or conditional clearance level. Here it is generally accepted not to consider radionuclides that contribute less than $10 \%$ to the annual effective dose of $10 \mu \mathrm{Sv}$.

Clearing of material means that the material is released from any future regulatory control and subsequently needs an authorization by the competent authorities. It also means that for any decommissioning of an accelerator the practical conditions must be fixed under which materials can be cleared and that necessary checks in the dismantling phase are performed by an independent controlling body. The administrative and technical procedures for clearance generally are lengthy in time but in practice CLs for materials with half-lives shorter than 60 days are not required. In fact, due to the initial fast decay of radioactivity from the accelerator environment the IAEA EVs could be used for all short-lived radionuclides without significantly increasing the radiological hazard to people getting in contact with the material.

Table 2. Comparison of exemption values and clearance levels in $\mathrm{Bq} / \mathrm{g}$ for commonly identified long-lived radionuclides (Half-live $>60$ days) in activated materials around high-energy accelerators. For an explanation of the columns see text.

\begin{tabular}{|c|c|c|c|c|}
\hline 1 & 2 & 3 & 4 & 5 \\
\hline Nuclide & EV $(1,2)$ & UCL (3) & LE (4) & CLF (5) \\
\hline $3 \mathrm{H}$ & $10^{6}$ & $3 \cdot 10^{3}$ & $3 \cdot 10^{2}$ & $10^{4}$ \\
\hline${ }^{14} \mathrm{C}$ & $10^{4}$ & $3 \cdot 10^{2}$ & 20 & $10^{3}$ \\
\hline${ }^{22} \mathrm{Na}$ & 10 & 0.3 & 3 & 1 \\
\hline${ }^{26} \mathrm{Al}$ & $?$ & $?$ & 2 & $?$ \\
\hline $36 \mathrm{Cl}$ & $10^{4}$ & $3 \cdot 10^{2}$ & 10 & $10^{3}$ \\
\hline${ }^{44} \mathrm{Ti}$ & $?$ & $?$ & 1 & $?$ \\
\hline${ }^{46} \mathrm{Sc}$ & 10 & $?$ & 5 & 1 \\
\hline${ }^{54} \mathrm{Mn}$ & 10 & 7 & 10 & 1 \\
\hline${ }^{55} \mathrm{Fe}$ & $10^{4}$ & $3 \cdot 10^{2}$ & 70 & $10^{3}$ \\
\hline $56 \mathrm{Co}$ & 10 & $?$ & 3 & 1 \\
\hline${ }^{57} \mathrm{Co}$ & $10^{2}$ & 30 & 30 & 10 \\
\hline${ }^{58} \mathrm{Co}$ & 10 & 3 & 10 & 1 \\
\hline${ }^{60} \mathrm{Co}$ & 10 & 0.3 & 1 & 1 \\
\hline${ }^{63} \mathrm{Ni}$ & $10^{5}$ & $3 \cdot 10^{3}$ & 50 & $10^{4}$ \\
\hline $65 \mathrm{Zn}$ & 10 & $?$ & 3 & 1 \\
\hline $108 \mathrm{~m} A g$ & 10 & $?$ & 5 & 1 \\
\hline $110 \mathrm{~m} A g$ & 10 & 0.3 & 3 & 1 \\
\hline${ }^{133} \mathrm{Ba}$ & $?$ & $?$ & 10 & $?$ \\
\hline${ }^{134} \mathrm{Cs}$ & 10 & 0.3 & 0.5 & 1 \\
\hline${ }^{137} \mathrm{Cs}$ & 10 & 0.3 & 0.7 & 1 \\
\hline${ }^{152} \mathrm{Eu}$ & 10 & 0.3 & 5 & 1 \\
\hline${ }^{154} \mathrm{Eu}$ & 10 & $?$ & 3 & 1 \\
\hline $204 \mathrm{Tl}$ & $10^{4}$ & $?$ & 10 & $10^{3}$ \\
\hline
\end{tabular}

For the practical clearing of material a most interesting approach is used in Switzerland. The "exemption limits" LE in column 4 of table 2 are actually clearance levels for disposal, recycling and reuse of radioactive material under the condition that the dose rate at $10 \mathrm{~cm}$ from the surface of the object is anywhere smaller than $0.1 \mu \mathrm{Sv} / \mathrm{h}$. This places the emphasis on the external radiation hazard of solid radioactive materials and means that due to this constraint in the case of big objects $L E$ values can be rarely directly applied in practice. In the case of a steel block of $1 \mathrm{~m}^{3}$ the corrected $\mathrm{LE}$ value drops to only $0.5 \mathrm{~Bq} / \mathrm{g}$ whilst for ${ }^{60} \mathrm{Co}$ the value is only $0.2 \mathrm{~Bq} / \mathrm{g}$ for an object of similar dimensions. Hence, these corrected LE values are rather close to the most conservative CLs in table 2. In addition, to be on the safe side the maximum value of specific activity in an extended object like a magnet should be lower than the LE value, thus guarantying that the overall specific activity of the object is always lower than LE. 
In France there are no UCLs either. However, for the decommissioning of nuclear installations the CEA has proposed a procedure that could be assimilated to conditional clearing (5). However, the French approach requires that the "non radioactivity" of a material is first established by reasoning. This means for an accelerator to collect all past information on operational scenarios like beam energies, intensities and possible loss pattern in the machine or beam lines and to perform appropriate calculations estimating the activity of radionuclides that could have been created. Their calculated concentrations are corrected for their halflives. If in certain parts of an accelerator complex to be dismantled these results turn out to be below the CLFs in column 5 of table 2 the material following an official authorization can be cleared as inactive. The CLFs are actually one tenth of the EVs European Directive except for tritium where the value is one hundredth of the EV (5). Measurements of specific activity in the course of the dismantling must always show lower values than those obtained by the generally pessimistic calculations.

\section{MANAGEMENT OF RADIOACTIVE MATERIAL}

Management of radioactive material from a high-energy accelerator environment is a continuous action. Obsolete activated vacuum chambers or radioactive cables are delivered for radioactive storage at any time whilst e. g. bigger parts like whole activated magnets come in during longer shut-down periods. Usually the material requires and is left in pre-storage for some radioactive cooling prior to any further handling. However, before conditioning takes place the first step should be a classification where the following scheme of Categories adopted at CERN is rather convenient and practical.

In Category I falls material where in a relatively short time (up to a year) the specific radioactivity will have dropped below agreed clearance levels. Category II comprises all material where the analysis of the radionuclides involved shows that the specific activity will drop below clearance levels after 30 years of cooling. For this Category an approximate upper limit of specific activity for material that underwent an initial radioactive cooling time of at least one year is $100 \mathrm{~Bq} / \mathrm{g}$. Finally, in Category III all material of higher activity is placed subject to release as radioactive waste.

Following conditioning which in most cases means material separation, cutting and volume reduction, radioactive material of Category II must be kept for longer periods before its release as non-active. Whole magnets or other complex accelerator elements are rather dismounted to separate materials but also in view of taking off any Category III items of higher activity. Big pieces are sometimes also cut to ease future handling. Aluminium vacuum chambers are pressed to cubes. The insulation is either cut off cables or becomes separated from the metal when cables are shredded and generally falls into Category I. Eventually most of the material is collected in storage containers according to material type and activity level. In many cases dose rate measurements at $10 \mathrm{~cm}$ for a given storage geometry combined with measurements of specific activity give rather reliable information on the total activity stored in a container.

Category II materials have been analyzed at CERN's high-energy accelerators following several years of irradiation and 5 to 10 years of radioactive cooling. The percentage distribution of the long-lived radionuclides naturally depends on the actual material composition (Stainless steel and concrete could vary quite a bit), the irradiation type (direct proton or neutron radiation), and exposure (intensity and timely pattern). It is quite obvious that in practice the important radionuclides for material activated in an accelerator environment are ${ }^{60} \mathrm{Co}$ in the case of iron, copper and stainless steel ( 80 to $98 \%$ ). ${ }^{22} \mathrm{Na}$ is determined in the case of aluminum (100\%) and concrete ( 38 to $95 \%$ ) where ${ }^{152} \mathrm{Eu}$ could be the dominant radionuclide in concrete or earth (2 to $52 \%$ ) after ${ }^{22} \mathrm{Na}$ has decayed. Following an additional cooling time of 20 years the activity in all of the materials analyzed will have decayed below a total specific activity of $1 \mathrm{~Bq} / \mathrm{g}$.

Eventually, following conditioning, Category III material could in principle be shipped in containers that fulfil the local requirements for long term storage to radioactive waste depositaries. At present it seems, however, that, whilst appropriate storage centers accept waste from the nuclear cycle, there is some hesitation with respect to radioactive waste of what is considered unknown composition from the high-energy accelerator environment.

\section{CONCLUSIONS}

Radioactive material from a high-energy accelerator environment is mainly metallic in nature with the spectrum of induced radionuclides well known. The radiation hazard from such activated material is predominantly an external one. In view of the small radiological hazard posed by material of very low specific activity it should be subject to recycling rather than to waste disposal. It is regrettable that at present no unique internationally accepted system of clearance levels exists.

\section{REFERENCES}

1. International Atomic Energy Agency, International Basic Safety Standards for Protection against Ionizing Radiation and for the Safety of Radiation Sources, Safety Series No 115-I (1994)

2. Directive 96/29/Euratom du Conseil du 13 mai 1996 fixant les normes de base relatives à la protection sanitaire de la population et des travailleurs contre les dangers résultant des rayonnements ionisants, Journal officiel des communautés européennes, No L. 159 du 29 juin 1996, page 1, (1996)

3. International Atomic Energy Agency, Clearance levels for radionuclides in solid materials, IAEA-TECDAO-855 (1996).

4. Ordonnance suisse sur la radioprotection, Berne, octobre (1994).

5. Principes concernant la gestion des déchets de très faible radioactivité, Circulaire $N^{\circ} 5-A$, Manuel CEA de la Sûreté Nucléaire, CEA-DSQN, (1997). 